\title{
MiR-1 Suppresses Proliferation of Osteosarcoma Cells by Up-regulating p21 via PAX3
}

\author{
RYOTA FUJII*, EIJI OSAKA*, KENTARO SATO and YASUAKI TOKUHASHI
}

Department of Orthopaedic Surgery, Nihon University School of Medicine, Tokyo, Japan

\begin{abstract}
Background/Aim: miRNA-1(miR-1) is downregulated in various cancer cells including osteosarcoma cells. This study was conducted to analyze the function of miR-1 in osteosarcoma cells. Materials and Methods: miR-1 expression in osteosarcoma cells was evaluated by qRT-PCR. Cell proliferation was evaluated after transfecting miR-1 by WST8 assay and FACS analysis, both in vitro and in vivo. Results: Overexpression of miR-1 suppressed cell proliferation and induced cell-cycle arrest in the $G_{0^{-}} G_{1}$ phase by increasing $p 21$ levels via a p53-independent pathway. Overexpression of miR-1 down-regulated $P A X 3$, a potential p21-regulating gene. Moreover, knockdown of PAX3 suppressed cell proliferation by increasing p21 levels, and induced arrest at the $G_{0} / G_{1}$ phase. Administration of miR-1 showed an in vivo antitumor effect. Conclusion: Overexpression of miR-1 suppressed cell proliferation and induced arrest in the $G_{0} / G_{1}$ phase by increasing 21 levels via a p53-independent pathway through $P A X 3$ suppression. These results indicate that miR-1 could be a therapeutic target for osteosarcoma.
\end{abstract}

Osteosarcoma is a primary bone malignancy that usually occurs in the metaphyseal region of long bones in children and adolescents, producing immature osteoids and bones. Previously, amputation of the extremities, concurrent with detection, was the conventional therapy for osteosarcoma and the 5-year survival rate was extremely poor, less than $20 \%$, due to the inability to inhibit pulmonary metastases (1). Recently, the survival rate has increased to $60-80 \%$ through the application of combination treatments using surgery and

This article is freely accessible online.

*These Authors contributed equally to this study.

Correspondence to: Eiji Osaka, Department of Orthopaedic Surgery, Nihon University School of Medicine, 30-1 Oyaguchikami-cho, Itabashi-ku, Tokyo 173-8610, Japan. Tel: +81 339728111, Fax: +81 339724824, e-mail: osaka.eiji@nihon-u.ac.jp

Key Words: Osteosarcoma, miR-1, p21, PAX3, p53-independent pathway. chemotherapy, but no major developments in treatment have occurred over the last 30 years. Furthermore, 1/3 of osteosarcoma patients experience local relapses and distal metastases even after potent chemotherapy, and the mean survival after relapse is less than 1 year $(2,3)$. Osteosarcoma is characterized by high genomic instability, and many individually different genome translocations, amplifications, and defects are observed. For these reasons, no uniform pathogenic events leading to tumorigenesis have been established (4). Therefore, further improvements in the prognosis of osteosarcoma will require clarification of the mechanisms involved in tumorigenesis.

MicroRNAs (miRNAs) are small non-coding RNAs, 19 to 24 bases long, which regulate gene expression by binding to 3'-UTR of the mRNA of target genes. Several studies have revealed that miRNAs play critical roles in various cancers and diseases. They act as oncogenes or tumor suppressors depending on the target genes. More than 1,000 miRNAs have been reported to date, and they regulate $30-90 \%$ of gene expression, playing a vital role in biological function (5). Abnormal miRNA expression is involved in carcinogenesis in various cancers, including osteosarcoma. The expression pattern is cancer-specific, and research focusing on the role of miRNAs in diagnosis, prognosis, drug resistance, and as novel therapeutic approaches has already begun (5-7). Since molecular-targeted drugs and antibody drugs exhibit one-toone relationships with target genes, they may not have the expected effect in the body, which is composed of many different cells and organs. Conversely, since miRNAs simultaneously target several expressed genes, it is believed that they can be effective in normalizing defective biological networks in their entirety (7).

Growing evidence has indicated the involvement of miRNAs in the tumorigenesis and metastases of osteosarcoma. Previous studies have reported that miR-34, -29b, -422a, -140, -133 , and -1 are involved in the regulation of various cell functions, and that they suppress proliferation, migration, and invasion $(6,8-11)$. It is known that miR-1 acts on mesenchymal stem cells and plays a critical role in skeletal and cardiac muscle development (12). Therefore, we focused on miR-1 under the hypothesis that it is involved in the 
mechanisms controlling the development and progression of osteosarcoma, which is of musculoskeletal in origin. The expression of miR-1 is decreased in various cancers $(13,14)$, and miR-1 acts as a tumor suppressor, being involved in diverse biological processes including tumor cell proliferation, migration, invasion, apoptosis, and cell cycle arrest. Overexpression of miR-1 is believed to play an important role in osteosarcoma and oncology treatments (14-17).

Studies have reported that miR-1 suppresses proliferation, migration, and invasion by down-regulating MET (11), Med1 and Med31 (18), and VEGFA (19) in osteosarcoma. Although some studies have reported that miR-1 induces cell cycle arrest, a detailed analysis on downstream genes related to the cell cycle has not been fully performed, and evidence concerning the in vivo function of miR-1 has not been obtained.

The aim of this study was to analyze the role of miR-1 in osteosarcoma, and to identify and analyze the functions of new target genes related to cell proliferation and cell cycle. The study also aimed to analyze changes in cell proliferation after transfection with miR-1 using a xenograft model to evaluate the in vivo antitumor effect of miR-1.

\section{Materials and Methods}

Osteosarcoma cell lines and normal osteoblast cell line. Human osteosarcoma MG63, Saos2, and G292 cell lines were purchased from the Health Science Research Resource Bank of Japan (Osaka, Japan). The normal osteoblast cell line hFOB1.19 was purchased from ATCC (Manassas, VA, USA). For MG63 and hFOB1.19, Dulbecco's Modified Eagle's Medium (DMEM) (Nacalai Tesque, Kyoto, Japan) containing $10 \%$ fetal bovine serum (Nichirei Bioscience, Tokyo, Japan), $0.1 \mathrm{mM}$ non-essential amino acids (Thermo Fisher Scientific, Waltham, MA, USA), and $100 \mathrm{IU} / \mathrm{ml}$ penicillin-streptomycin-glutamine (Thermo Fisher Scientific) was used. For Saos2 and G292, McCoy's 5A medium (Nacalai Tesque) containing $10 \%$ fetal bovine serum, $0.1 \mathrm{mM}$ non-essential amino acids, and $100 \mathrm{IU} / \mathrm{ml}$ penicillin-streptomycin-glutamine was used. All cells were cultured at $37^{\circ} \mathrm{C}$ and $5 \% \mathrm{CO}_{2}$.

Transfection with miRNA-1 mimic and siRNA. The osteosarcoma cell line was transfected with miR-1 mimic (miR-1 group) and negative control miRNA (NC-miRNA group) at a final concentration of $50 \mathrm{nM}$ each using Lipofectamine ${ }^{\mathrm{TM}} 2000$ Transfection Reagent (Thermo Fisher Scientific) according to the manufacturer's instructions. Transfection with PAX3-siRNA and negative control-siRNA (Thermo Fisher Scientific) were performed at a final concentration of $10 \mathrm{nM}$ in the same manner.

The sequences were as follows: has-miR-1: 5'-UGGAAUGUAA AGAAGUAUGUAU-3', PAX3-siRNA-Sense: 5'-GAGACAAAU UACUCAAGGATT-3', PAX3-siRNA-Antisense: 5'-UCCUUG AGUAAUUUGUCUCGG-3'.

Quantitative RT-PCR. After transfection with miRNA for $48 \mathrm{~h}$, total RNA was extracted from cells using a RNeasy Mini Kit (Qiagen, Hilden, Germany) according to the manufacturer's instructions. The extracted total RNA was reverse transcribed using Prime Script RT
Master Mix (Takara Bio Inc, Shiga, Japan) to prepare complementary DNA (cDNA) at a final concentration of $500 \mathrm{ng} / \mu \mathrm{l}$. The reaction was performed using Takara Prime Script (Takara Bio Inc) according to the manufacturer's instructions. The analysis of expression levels by qRT-PCR was performed using a TaqMan Probe (Takara Bio Inc) according to the manufacturer's instructions. Expression levels were corrected using RUN44 (Thermo Fisher Scientific) as an endogenous control. Synthesized cDNA was used to perform qRT-PCR, and the expression levels of p21, PAX3, and glyceraldehyde 3-phosphate dehydrogenase (GAPDH) were analyzed. All reactions were performed using a SYBR Premix Ex Taq II (Takara Bio Inc) according to the manufacturer's instructions.

The specific primers were as follows: RUN44: 5'-AGCTAAT TAAGACCTTCATGTTCA-3', p21-Forward: 5'-TGGACCTGTCA CTGTCTTGT-3', p21-Reverse: 5'-TCCTGTGGGCGGAT TAG-3', PAX3-Forward: 5'-GAAACACCGTGCCGTCA-3', PAX3-Reverse: 5'-ССТССТССТСТТСАССТT-3', GAPDH-Forward: 5'-TCACCA GGGCTGCTTTTAAC-3', GAPDH-Reverse: 5'-TGACGGTGCCA TGGAATTTG-3'.

For PCR reactions, expression levels were corrected by the $\triangle \triangle \mathrm{CT}$ method using GAPDH as an endogenous control. The statistical analysis was performed in triplicate $(n=3)$ and repeated 3 times.

Western blotting. The protein was extracted using a Pierce RIPA buffer (Thermo Fisher Scientific) and protease inhibitors (Roche Applied Science, Penzburg, Germany). The protein extract was concentrated and purified using Amicon Ultra filters (Merck Millipore, Billerica, MA, USA). The protein concentration was quantified using a BCA Protein Assay Kit (Thermo Fisher Scientific). $25 \mu \mathrm{g}$ of protein, were applied to each lane of NuPAGE 4-12\% Bis-Tris Protein Gel (Thermo Fisher Scientific) and transferred onto Immobilon-P membrane (Millipore, Burlington, MA, USA). The membrane was blocked with Blocking One (Nacalai Tesque) for $1 \mathrm{~h}$. Each primary antibody was diluted in Can Get Signal Immunoreaction Enhancer Solution 1 (GE Healthcare, Toyobo, Japan), and incubated overnight at $4^{\circ} \mathrm{C}$. The diluted concentrations of each antibody were as follows: Rabbit anti-p53 antibody (DO-1; Santa Cruz Biotechnology, Santa Cruz, CA, USA), anti-phosphorylated p53 antibody (Cell Signaling Technology), antip73 antibody (Cell Signaling Technology), anti-p21 antibody (Santa Cruz Biotechnologies, CA, USA) at 1:1,000; mouse anti-PAX3 antibody (Abcam, Bristol, England) at 1:1,000; and anti-GAPDH rabbit polyclonal antibody (Abcam) as the endogenous control at 1:2,500. After treatment with the primary antibodies, the membrane was washed with phosphate buffered saline containing $0.1 \%$ Tween (PBS-T), and then incubated with horseradish peroxidase (HRP)labelled anti-rabbit or mouse $\mathrm{IgG}$ antibody (GE Healthcare) secondary antibodies diluted in PBS-T at 1:2,000, for $1 \mathrm{~h}$ at room temperature. The signal was developed using Chemi-Lumi One Super (Nacalai Tesque) chemiluminescence and then visualized using a Bioimage Analyser LAS-4000 (Fujifilm, Osaka, Japan).

WST8 cell proliferation assay. Cell proliferation was determined using a WST8 assay. The osteosarcoma cell line was transfected with miR-1 (50 nM), NC-miRNA (50 nM), siPAX3 (10 nM) or NCsiRNA $(10 \mathrm{nM})$ and seeded onto a 96-well plate at a density of $5.0 \times 10^{3}$ cells $/ 100 \mu \mathrm{l} /$ well. After incubation for 24,48 , and $72 \mathrm{~h}, 10$ $\mu \mathrm{l}$ of Cell Count Reagent SF (Nacalai Tesque) was added to $90 \mu \mathrm{l}$ of the culture solution. Color was allowed to develop for 1-h and 
its absorbance (450 nM) was determined using a Wallac 1420 ARVO MX (PerkinElmer, Waltham, MA, USA). The experiment was performed in triplicate $(n=3)$ and repeated 3 times.

Flow cytometry (FACS analysis). The osteosarcoma cell line was transfected with miR-1 (50 nM), s NC-miRNA (50 nM), iPAX3 $(10 \mathrm{nM})$, or NC-siRNA $(10 \mathrm{nM})$ and seeded onto a 6 -well plate at a density of $1.0 \times 10^{5}$ cells $/ 2 \mathrm{ml} /$ well. After $48 \mathrm{~h}$ incubation, the cells were collected together with the floating cells. After washing with phosphate buffered saline (PBS), they were suspended in icechilled $75 \%$ ethanol, and kept for $\geq 12 \mathrm{~h}$ at $4^{\circ} \mathrm{C}$. After washing with PBS, the cells were suspended in $0.1 \%$ fetal bovine serum (Nichirei Bioscience). After incubation at room temperature for $15 \mathrm{~min}$ and following the administration of $200 \mu \mathrm{g} / \mathrm{ml}$ of RNase A, the cells were stained with propidium iodide. An analysis was performed using FACS Calibur (Becton, Dickinson and Company, NJ, USA) to determine the phase of cell cycle in each cell. The measurement was repeated 3 times for each sample, and the mean number of cells belonging to each phase of the cell cycle was calculated.

Animal studies. Eight-week male nude mice $(\mathrm{n}=12)$ were purchased from CLEA Japan, Inc. (Tokyo, Japn). The osteosarcoma cell line (MG63) was suspended in $200 \mu \mathrm{l}$ of culture solution to prepare $1.0 \times 10^{6}$ cells and subcutaneously injected to form a tumor. The tumor size was calculated as long diameter $\times$ short diameter $\times$ height $/ 2$. When the tumor volume reached $200 \mathrm{~mm}^{3}$, miR-1 $(25 \mathrm{nM})$ or NC-miRNA ( $25 \mathrm{nM})$ were administered around the tumor using Atelogene (Koken, Tokyo, Japan). miRNA was administered 3 times on Days 0,7 , and 14 . The tumor volume was measured every 2 to 3 days until the final measurement on Day 21. On Day 21, the tumor was removed. Subsequently, the tumor tissue was stained with Ki67 to asses proliferation activity. Ki67 staining was scored from 0 to 15 points using the following formulas in a $(1) \times(2)$ manner: (1) area (percentage of tumor cells per slide) rated as $0: 0 \% ; 1:<5 \% ; 2: 5 \%$ to $20 \% ; 3: 21 \%$ to $50 \% ; 4: 51 \%$ to $75 \%$; and $5:>75 \%$, and (2) density rated as 0 : absence; 1 : weak; 2 : moderate; and 3 : strong. These animal experiments were approved by the Animal Experiment Committee of Nihon University (Approval No. AP15M035). Each slide was scored by 3 persons other than experimenters.

Statistical analysis. All analyses were performed using $\mathrm{n} \geq 3$, and their mean values were analyzed. The statistical analysis was performed using GraphPad Prism5 software, and quantitative results were expressed as the mean \pm standard deviation (SD). For differences in the mean, $p$-values of $<0.05$ were considered statistically significant in the Student's $t$-test.

\section{Results}

Reduction of miR-1 expression in osteosarcoma cell lines compared to the normal cell line. To clarify the roles of miR1 in tumorigenesis and the progression of osteosarcoma, qRTPCR was conducted to evaluate the miR-1 expression level in osteosarcoma and normal osteoblast cell lines. Compared to the normal osteoblast cell line hFOB1.19, used as the control, all osteosarcoma cell lines, MG63, Saos2, and G292, showed a significant reduction in miR-1 expression $(p<0.05$, Figure 1A). After transfection of miR-1 to the osteosarcoma cell lines, miR-1 was overexpressed ( $p<0.05$, Figure 1B).
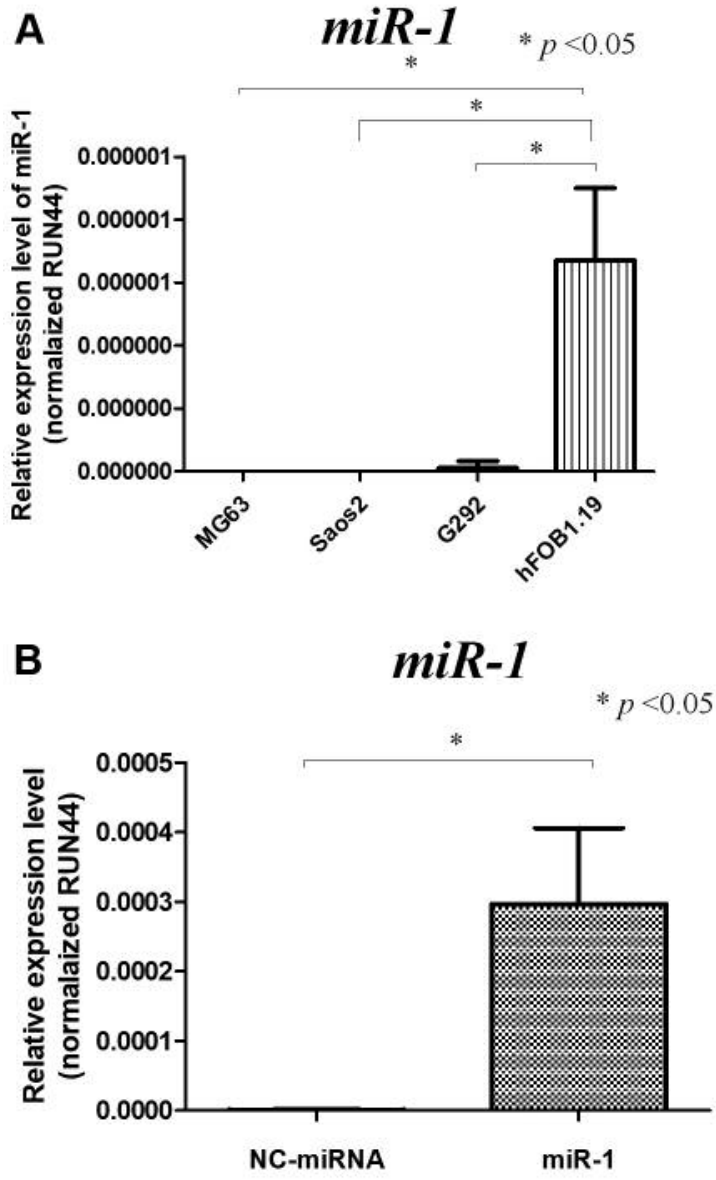

Figure 1. Expression level of miR-1. A: Expression levels of miR-1 in the osteosarcoma cell lines (MG63, Saos2, G292) and normal cell line (hFOB1.19). B: Changes in miR-1 expression levels 48 h after transfection of the osteosarcoma cell line MG63 with miR-1 (50 nM). *p<0.05.

Overexpression of miR-1 suppressed cell proliferation and induced cell-cycle arrest by increasing p 21 expression via a p53-independent pathway. To evaluate the role of miR-1 overexpression on tumor growth in osteosarcoma, the WST8 assay and a FACS analysis were conducted to evaluate cell proliferation and determine the distribution of cells in each phase of the cell cycle.

Overexpression of $m i R-1$ suppressed cell proliferation. Osteosarcoma cells were transfected with the miR-1 mimic or NC-miRNA for 24-72 $\mathrm{h}$. The WST8 assay revealed that the miR-1 group showed significant suppression of cell proliferation at 24,48 , and $72 \mathrm{~h}$ compared with the NCmiRNA group (Figure 2A).

Overexpression of miR-1 induced cell cycle arrest in the $G_{0^{-}}$ $G_{1}$ phase by increasing p21 expression. The FACS analysis 

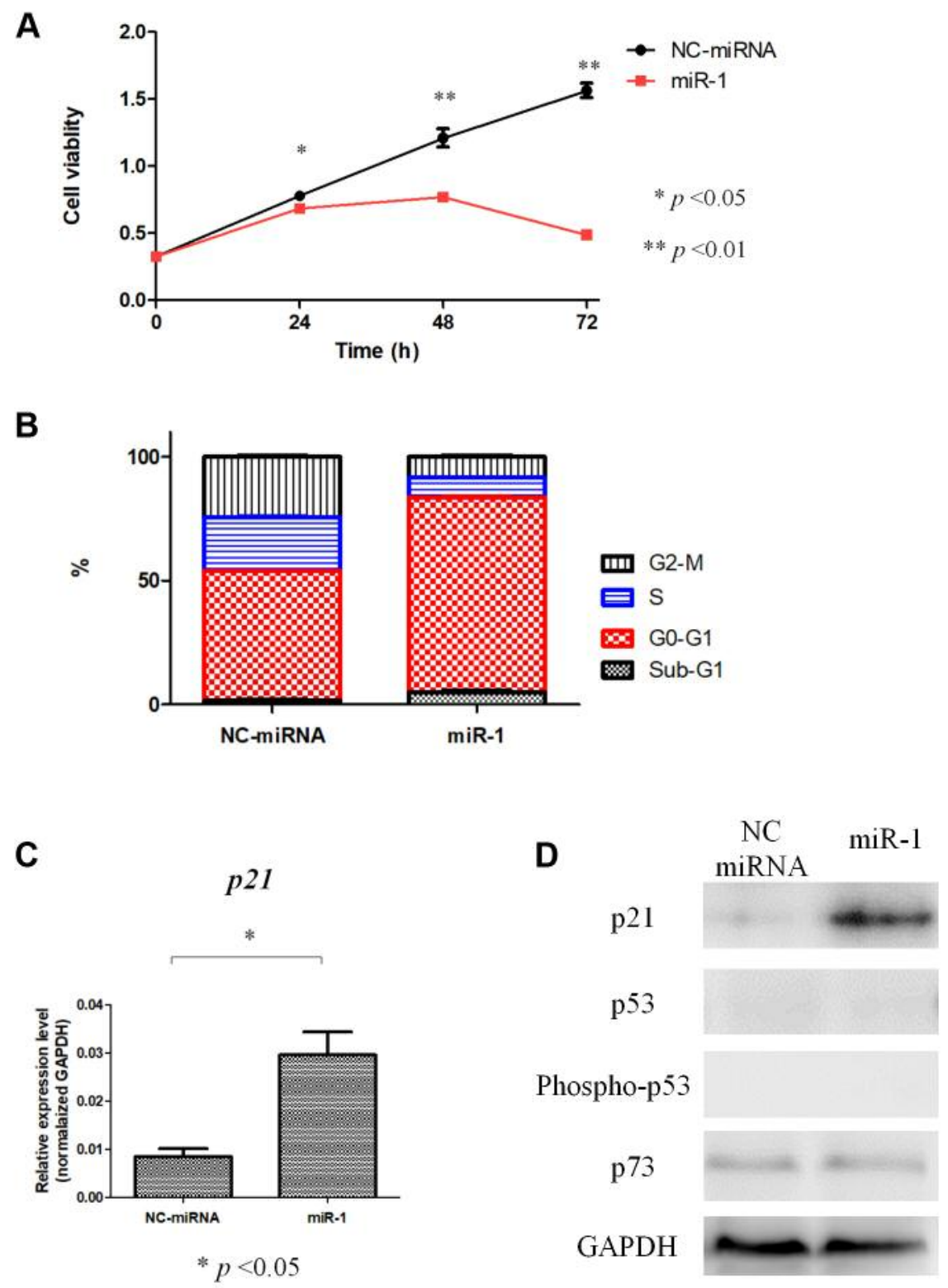

Figure 2. Evaluation of cell proliferation and cell cycle after transfection of miR-1 and NC-miRNA in the osteosarcoma cell line. A: Cell proliferation at 24, 48, and $72 \mathrm{hs}$. B: Phase of cell cycle at $48 \mathrm{~h}$. C: Analysis of p 21 expression levels by qRT-PCR. D: Western blot analysis of the expression of p21, p53, phosphorylated $p 53$, and $p 73$ at 48 h by. *p<0.05, **p<0.01.

miR-1 group showed a reduction in the number of cells in the $S$ phase and an increase in the number of cells in the $G_{0}-G_{1}$ phase (Figure 2B), suggesting cell cycle arrest in the $\mathrm{G}_{0}-\mathrm{G}_{1}$ phase. An analysis of the genes related to the cell cycle was performed to elucidate the mechanism of cell cycle arrest in the $\mathrm{G}_{0}-\mathrm{G}_{1}$ phase. A significant increase in $\mathrm{p} 21$ expression was shown in the qRT-PCR (Figure 2C). Although the western blot showed no changes in the expression of p53, p73, or phosphorylated p53, p21 expression increased significantly.
These results demonstrated that cell cycle arrest was induced via a p53-independent pathway (Figure 2D).

Overexpression of miR-1 down-regulated PAX3 expression. Since the obtained data showed that overexpression of miR1 acted on p21 and induced cell cycle arrest via a p53independent pathway, we focused on PAX3, one of the target genes of miR-1, as a potential p21-regulating gene (Figure $3 \mathrm{~A}$, Table I) (17). PAX3 is a member of the PAX gene family 

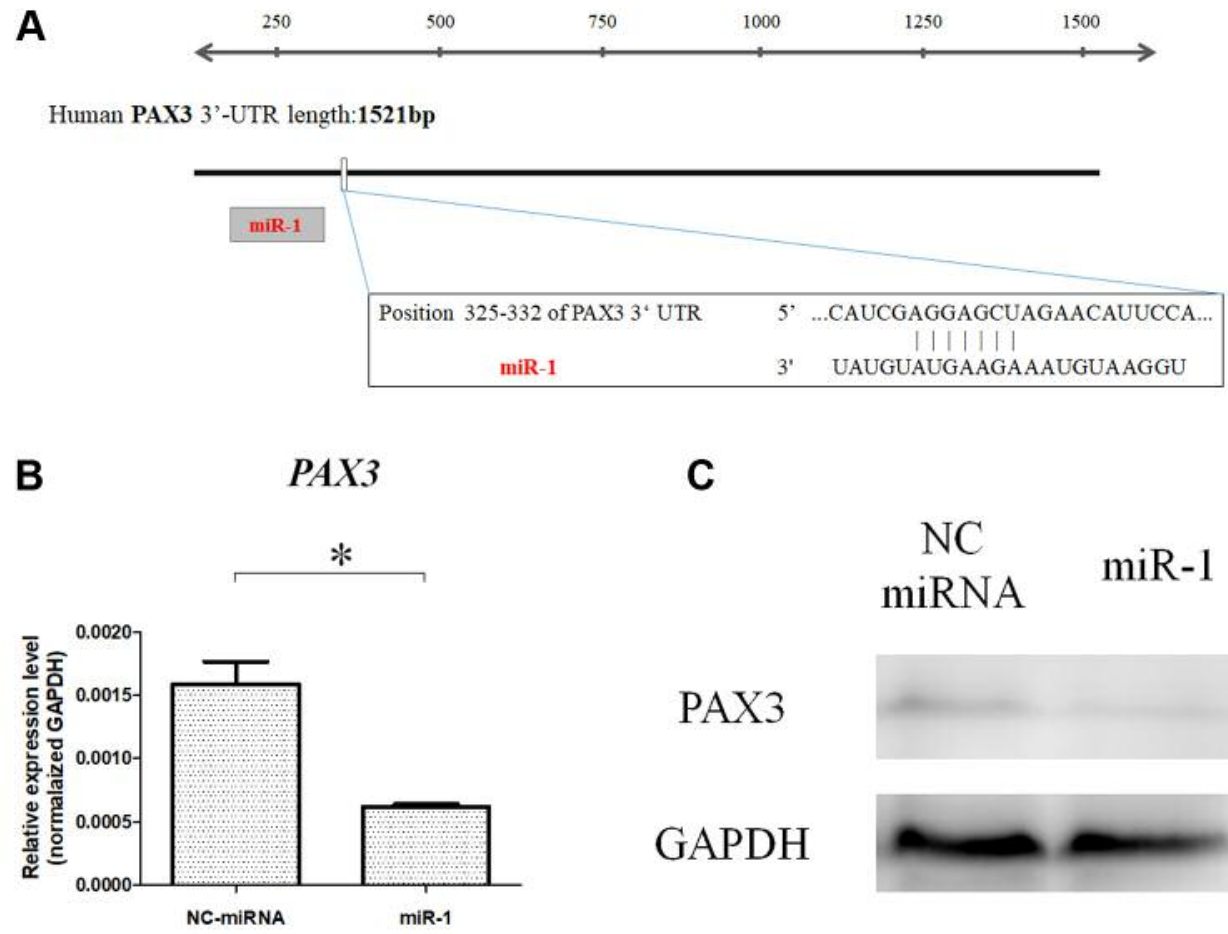

Figure 3. The effect of transfection of miR-1 or NC-miRNA in the osteosarcoma cell line (MG63) on PAX3 levels. A: The miR-1 sequence and target area in PAX3. B: qRT-PCR analysis of PAX3 expression at $48 \mathrm{~h}$ and C: western blot analysis of PAX3 expression at $48 \mathrm{~h}$.

Table I. Predicted direct targets of miR-1.

\begin{tabular}{|c|c|c|c|}
\hline Gene name & Official name & $\begin{array}{l}\text { Chromosome } \\
\text { location }\end{array}$ & Functions \\
\hline TAGLN2 & Transgelin 2 & $1 \mathrm{q} 21-\mathrm{q} 25$ & The earliest markers of differentiated smooth muscle \\
\hline CXCR4 & $\begin{array}{l}\text { Chemokine (C-X-C motif) } \\
\text { receptor } 4\end{array}$ & $2 \mathrm{q} 21$ & CXC chemokine receptor specific for stromal cell-derived factor- 1 \\
\hline FN1 & Fibronectin 1 & $2 q 34$ & Involved in cell adhesion and migration processes \\
\hline PAX3 & Paired box 3 & $2 q 35$ & A member of the paired box (PAX) family of transcription factors \\
\hline PTMA & Prothymosin, alpha & $2 q 37.1$ & Enhance cell-mediated immunity \\
\hline HDAC4 & Histone deacetylase 4 & $2 \mathrm{q} 37.3$ & Histone deacetylase activity and represses transcription \\
\hline FOXP1 & Forkhead box P1 & $3 \mathrm{p} 14.1$ & $\begin{array}{c}\text { The regulation of tissue- and cell type-specific gene transcription } \\
\text { during both development and adulthood }\end{array}$ \\
\hline VEGFA & $\begin{array}{l}\text { Vascular endothelial } \\
\text { growth factor A }\end{array}$ & $6 \mathrm{p} 21$ & $\begin{array}{l}\text { A growth factor activate in angiogenesis, } \\
\text { vasculogenesis, endothelial cell growth }\end{array}$ \\
\hline Pim-1 & Pim-1 oncogene & $6 \mathrm{p} 21.2$ & Signal transduction \\
\hline ET-1 & Endothelin 1 & $6 \mathrm{p} 24.1$ & A potent vasoconstrictor \\
\hline MET & Met proto-oncogene & $7 \mathrm{q} 31$ & Proto-oncogene \\
\hline Slug & Snail family zinc finger 2 & $8 \mathrm{q} 11$ & A member of the Snail family of $\mathrm{C} 2 \mathrm{H} 2$-type zinc finger transcription factors \\
\hline CXCL12 & Chemokine (C-X-C motif) ligand 12 & $10 \mathrm{q} 11.1$ & $\begin{array}{c}\text { The ligand for the G-protein coupled receptor, } \\
\text { chemokine (C-X-C motif) receptor } 4\end{array}$ \\
\hline ETS1 & $\begin{array}{l}\text { v-ets avian erythroblastosis virus } \\
\text { E26 oncogene homolog } 1\end{array}$ & $11 \mathrm{q} 23.3$ & A member of the ETS family of transcription factors \\
\hline TWF1 & Twinfilin actin-binding protein 1 & $12 \mathrm{q} 12$ & An actin monomer-binding protein \\
\hline CCND2 & Cyclin D2 & $12 \mathrm{p} 13$ & Regulators of CDK kinases \\
\hline SRSF9 & Serine/arginine-rich splicing factor 9 & $12 \mathrm{q} 24.31$ & $\begin{array}{l}\text { A member of the serine/arginine (SR)-rich family } \\
\text { of pre-mRNA splicing factors }\end{array}$ \\
\hline PNP & Purine nucleoside phosphorylase & $14 \mathrm{q} 13.1$ & The phosphorolysis of purine nucleosides \\
\hline
\end{tabular}




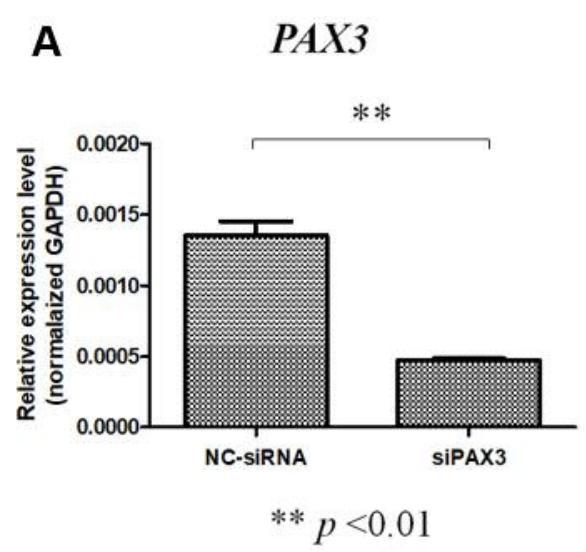

C

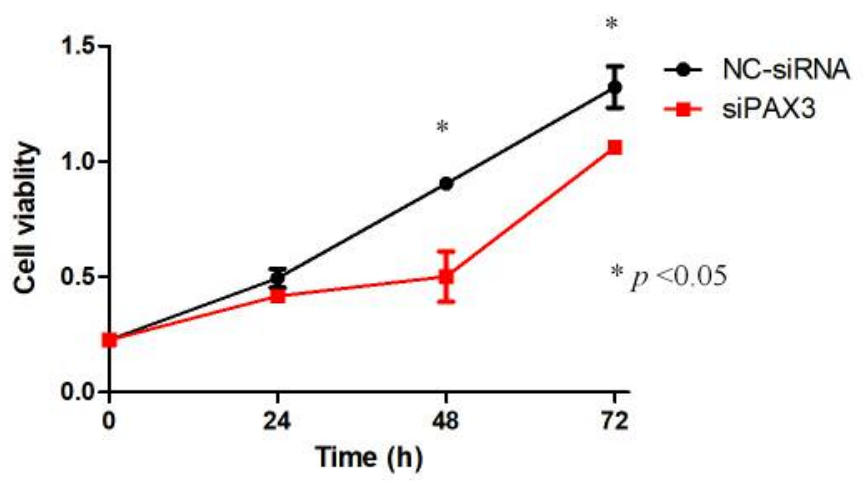

E

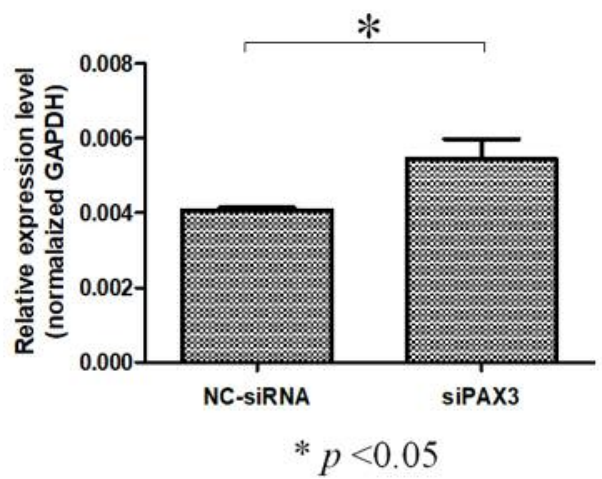

B

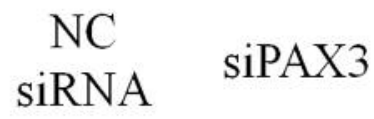

PAX3

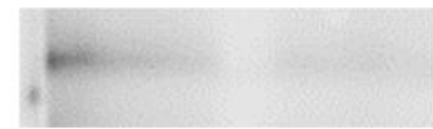

GAPDH

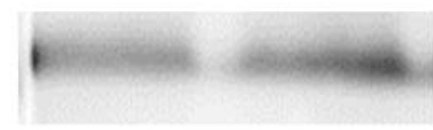

Sub-G1

$\bowtie 0-G 1$

ㅁ

而 G2-M

Figure 4. Evaluation of cell proliferation and cell cycle after transfection of siPAX3 and NC-siRNA (10 nM) in the osteosarcoma cell line. A: qRTPCR analyses of PAX3 expression at $48 \mathrm{~h}$. B: Western blot analysis of PAX3 expression at $48 \mathrm{~h}$. C: Cell proliferation at 24, 48, and 72 h. D: Distribution of cells in each phase of the cell cycle at 48 h. E: qRT-PCR analysis of p21 expression levels and F: western blot analysis of p21 expression levels. ${ }^{*} p<0.05,{ }^{*} p<0.01$.

that is involved in cell proliferation, invasion, survival, and cell lineage differentiation during fetal life (20), as well as in the regulation of cell cycle via p21 (21). In osteosarcoma, high expression of PAX3 was found to promote cell migration and invasion (22). However, there have been no studies examining cell proliferation in osteosarcoma. In this study the effect of miR-1 transfection on PAX3 in osteosarcoma was evaluated. qRT-PCR and Western blot analysis indicated that PAX3 expression decreased after transfection with miR-1 (Figure 3B and C). 
A

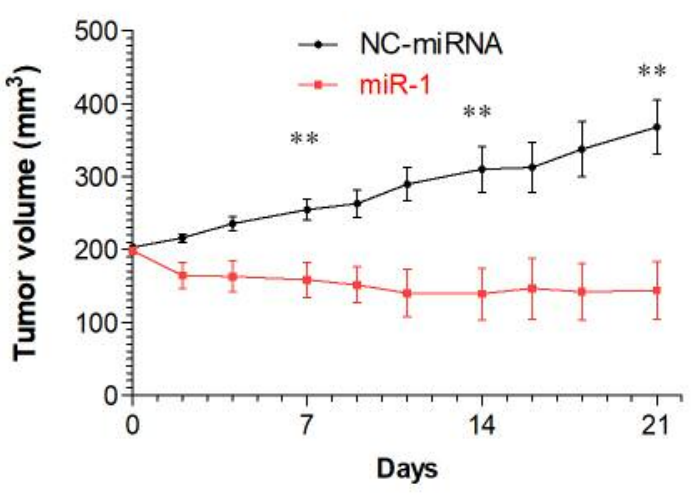

B

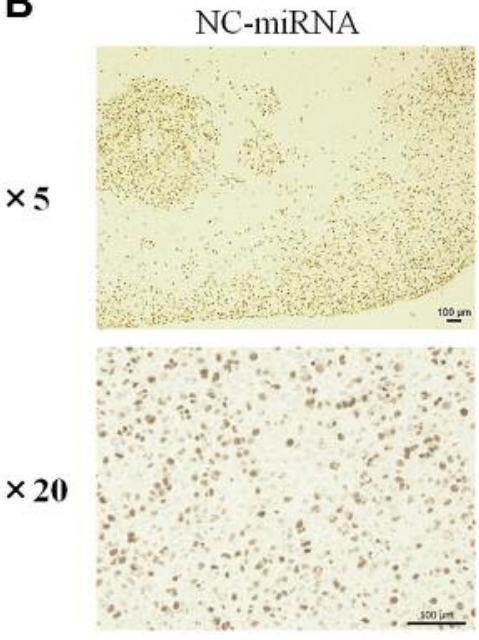

$* * p<0.01$

miR-1

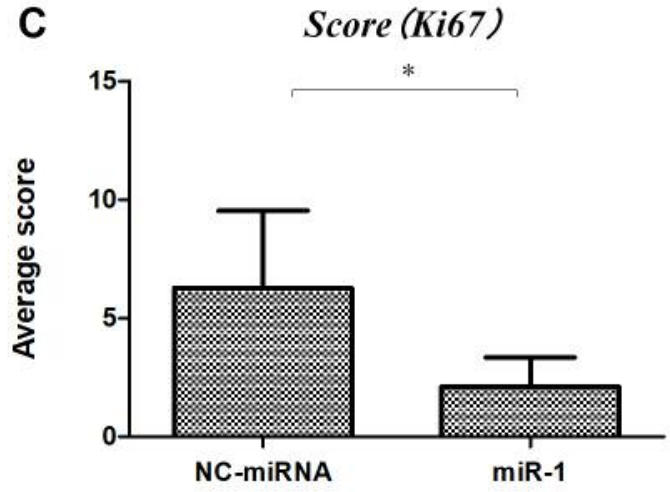

${ }^{*} p<0.05$

Figure 5. The mouse subcutaneous tumor model was prepared, and miR-1 or NC-miRNA were administered around the tumor (each n=6). miRNA 3 times on Days 0, 7, and 14. A: Changes in tumor volume over time. B: Tumor appearance C: Ki67 staining of tumor tissues. D: Evaluation of proliferation activity by scoring. $* p<0.05, * * p<0.01$.

Down-regulation of PAX3 expression inhibited cell proliferation via p21. PAX3-siRNA (siPAX3 group) was used to evaluate whether PAX regulated p21 in osteosarcoma. Cell proliferation and the phases of cell cycle were evaluated using the WST8 assay and FACS analysis.

Down-regulation of PAX3 expression suppressed cell proliferation. In the siPAX3 group, qRT-PCR and western blot analysis indicated that PAX3 expression was decreased (Figure 4A and B). Subsequently, cell proliferation was evaluated in the siPAX3 group. Cell proliferation tended to be suppressed at $24 \mathrm{~h}$ after transfection, compared to the NCsiRNA group, and significant suppression of cell proliferation was noted at 48 and $72 \mathrm{~h}$ (Figure 4C).

Down-regulation of $P A X 3$ expression induced cell cycle arrest in the $G_{0}-G_{1}$ phase by increasing p21 expression in the same manner as overexpression of $m i R-1$. FACS analysis showed that down-regulation of PAX3 (siPAX3 group) expression resulted in a reduction in the number of cells in the $S$ phase and an increase in the number of cells in the $G_{0^{-}}$ $\mathrm{G}_{1}$ phase (Figure $4 \mathrm{D}$ ), in the same manner as in the miR-1 group. In addition, qRT-PCR and western blot analysis showed that down-regulation of PAX3 expression results in increased p21 expression (Figure 4E and F).

miR-1 transfection suppressed tumor volume enlargement. Since miR-1 transfection suppressed cell proliferation, we evaluated the effect of miR-1 in tumorigenesis of osteosarcoma in vivo. In the miR-1 group, tumor enlargement was significantly suppressed on Days 7, 14, and 21. On Day 21 specifically, the tumor volume was $368.0 \pm 91.3 \mathrm{~mm}^{3}$ in the NC-miRNA group, whereas it was $144.1 \pm 96.0 \mathrm{~mm}^{3}$ in the miR-1 group, (Figure 5A and B). Immune staining with Ki67 
was performed to evaluate proliferation activity after miR-1 transfection. Proliferation activity was $6.3 \pm 3.3$ in the NCmiRNA group, compared to $2.1 \pm 1.2$ in the miR-1 group, showing a significant suppression of proliferation activity (Figure 5C and D).

\section{Discussion}

In osteosarcoma, many miRNAs are reportedly involved in the regulation of various cellular functions and the suppression of proliferation, migration, and invasion $(6,8$ 11). Among miRNAs, miR-1 has been shown to act on mesenchymal stem cells and to play a critical role in skeletal and cardiac muscle development (12). MiR-1 acted on the various targeted genes shown in Table I in a variety of cancers and influenced proliferation, cell cycle, apoptosis, neoangiogenesis, cell migration, cell invasion, EMT, and drug sensitivity (14-17). In spite of such findings, the exact mechanism of miR-1 has not yet been clarified. We hypothesized that miR-1 plays a critical role in the mechanism of the development of osteosarcoma, a mesenchymal tumor. The expression level of miR-1 is decreased in various cancers, including osteosarcoma (13, 14). A previous study has shown that the expression of miR-1, $-133 \mathrm{~b}$, and -378 was significantly reduced in such cases compared to the bone tissues of healthy subjects. Moreover, in tissue specimens, expression of miR-1 was decreased in high-grade specimens compared to low-grade specimens, showing a correlation to malignancy (11). This study confirmed that miR-1 expression was down-regulated in osteosarcoma and that cell proliferation was suppressed by overexpression of miR-1. The experiment in which miR1 was administered to the mouse subcutaneous tumor model revealed that miR-1 has a significant in vivo antitumor effect.

Since the effect of miR-1 overexpression on tumor growth in osteosarcoma has not been clarified, cell proliferation and cell cycle were analyzed. Overexpression of miR-1 has been shown to suppress cell proliferation in many cancers; the results of this study were consistent with these past studies $(14,15,17)$. Previous studies have reported that miR-1 suppresses proliferation, migration, and invasion by down-regulating MET (11), Med1 and Med31 (18), and VEGFA (19) in osteosarcoma. Although some studies have reported that miR-1 induced cell-cycle arrest in the $\mathrm{G}_{0}-\mathrm{G}_{1}$ phase by targeting MET, Med1 and Med31, a detailed analysis of the downstream genes related to the cell cycle has not been fully performed. The function of miR-1 in the cell cycle differs depending on the type of carcinoma: miR-1 induced arrest in the $G_{0} / G_{1}$ phase in lung cancer, head and neck squamous cell carcinoma, renal cell carcinoma, rhabdomyosarcoma, and $\mathrm{G}_{2}$ phase arrest in hepatoma $(13,17,23-25)$. It has also been reported that
miR-1 suppresses cell proliferation through arrest in the $\mathrm{G}_{0} / \mathrm{G}_{1}$ phase by down-regulating the expression of MET, CCND2, CDK4, and CDK6 $(11,24,26)$. In this study, overexpression of miR-1 significantly suppressed cell proliferation and induced arrest in the $G_{0} / G_{1}$ phase in the same manner. Therefore, an analysis of genes related to the cell cycle was performed to further elucidate the mechanism of action of miR-1. An important gene that induces arrest in the $\mathrm{G}_{0} / \mathrm{G}_{1}$ phase is p53 (27), and also, p21 expression increases via the p53 pathway (28). However, this study revealed that miR-1 induced cell cycle arrest by increasing p21 expression via a p53-independent pathway. Although p21 is regulated by various miRNAs, it is not a direct target of miR-1. Therefore, we focused on PAX3 as a potential p21-regulating gene (17). PAX3 is a member of the PAX gene family and is involved in cell proliferation, invasion, survival, and cell lineage differentiation during fetal life (20). It also regulates the cell cycle in neuroblastoma via p21 (21). In osteosarcoma, PAX3 expression is higher than in normal cells and a high level of expression of PAX3 promotes cell migration and invasion (22). Furthermore, high expression of PAX3 was associated with poor prognosis in glioma (29). In osteosarcoma, overexpression of miR-1 suppressed PAX3 expression and knockdown of PAX3 suppressed cell proliferation, increased p21 expression, and induced arrest in the $G_{0} / G_{1}$ phase. Therefore, in osteosarcoma, overexpression of miR-1 induced arrest in the $G_{0} / G_{1}$ phase by increasing $p 21$ expression via a p53-independent pathway through suppression of PAX3 expression. In the mouse subcutaneous tumor model, administration of miR-1 showed an in vivo antitumor effect. The results of this study suggest that miR1 could be a therapeutic target for osteosarcoma.

\section{Conclusion}

In osteosarcoma, overexpression of miR-1 suppressed cell proliferation by increasing p21 expression via a p53 familyindependent pathway through down-regulation of PAX3 expression. Furthermore, miR-1 showed a marked suppressive effect on tumor enlargement in a mouse subcutaneous tumor model. Therefore, miR-1 could be a new therapeutic target for osteosarcoma.

\section{Conflicts of Interest}

No potential conflicts of interest were reported by the Authors.

\section{Acknowledgements}

The Authors would like to thank Dr. Kyoko Fujiwara for her helpful advice on various technical supports. This study was supported from grant of Japan Orthopaedic and Traumatology Research Foundation Inc. No. 316 by Dr. Eiji Osaka. 


\section{References}

1 Uribe-Botero G, Russell WO, Sutow WW and Martin RG: Primary osteosarcoma of bone. Clinicopathologic investigation of 243 cases, with necropsy studies in 54. Am J Clin Pathol 67(5): 427-435, 1977.

2 Bielack SS, Kempf-Bielack B, Delling G, Exner GU, Flege S, Helmke K, Kotz R, Salzer-Kuntschik M, Werner M, Winkelmann W, Zoubek A, Jurgens $\mathrm{H}$ and Winkler $\mathrm{K}$ : Prognostic factors in high-grade osteosarcoma of the extremities or trunk: an analysis of 1,702 patients treated on neoadjuvant cooperative osteosarcoma study group protocols. J Clin Oncol 20(3): 776-790, 2002.

3 Kempf-Bielack B, Bielack SS, Jurgens H, Branscheid D, Berdel WE, Exner GU, Gobel U, Helmke K, Jundt G, Kabisch H, Kevric M, Klingebiel T, Kotz R, Maas R, Schwarz R, Semik M, Treuner J, Zoubek A and Winkler K: Osteosarcoma relapse after combined modality therapy: an analysis of unselected patients in the Cooperative Osteosarcoma Study Group (COSS). J Clin Oncol 23(3): 559-568, 2005.

4 Szuhai K, Cleton-Jansen AM, Hogendoorn PC and Bovee JV: Molecular pathology and its diagnostic use in bone tumors. Cancer Genet 205(5): 193-204, 2012.

5 Di Leva G, Garofalo M, Croce CM: MicroRNAs in cancer. Annu Rev Pathol 9: 287-314, 2014.

6 Miao J, Wu S, Peng Z, Tania M and Zhang C: MicroRNAs in osteosarcoma: diagnostic and therapeutic aspects. Tumour Biol 34(4): 2093-2098, 2013.

7 Tutar L, Tutar E, Ozgur A and Tutar Y: Therapeutic Targeting of microRNAs in Cancer: Future Perspectives. Drug Dev Res 76(7): 382-388, 2015.

8 He C, Xiong J, Xu X, Lu W, Liu L, Xiao D and Wang D: Functional elucidation of miR-34 in osteosarcoma cells and primary tumor samples. Biochem Biophys Res Commun 388(1): 35-40, 2009.

9 Song B, Wang Y, Xi Y, Kudo K, Bruheim S, Botchkina GI, Gavin E, Wan Y, Formentini A, Kornmann M, Fodstad O and Ju $\mathrm{J}$ : Mechanism of chemoresistance mediated by miR-140 in human osteosarcoma and colon cancer cells. Oncogene 28(46): 4065-4074, 2009.

10 Bahador R, Taheriazam A, Mirghasemi A, Torkaman A, Shakeri M, Yahaghi E and Goudarzi PK: Tissue expression levels of miR$29 \mathrm{~b}$ and miR-422a in children, adolescents, and young adults' age groups and their association with prediction of poor prognosis in human osteosarcoma. Tumour Biol 37(3): 3091-3095, 2016.

11 Novello C, Pazzaglia L, Cingolani C, Conti A, Quattrini I, Manara MC, Tognon M, Picci P and Benassi MS: miRNA expression profile in human osteosarcoma: role of miR-1 and miR-133b in proliferation and cell cycle control. Int J Oncol 42(2): 667-675, 2013.

12 Townley-Tilson WH, Callis TE and Wang D: MicroRNAs 1, 133, and 206: critical factors of skeletal and cardiac muscle development, function, and disease. Int $\mathrm{J}$ Biochem Cell Biol 42(8): 1252-1255, 2010.

13 Nohata N, Hanazawa T, Enokida $\mathrm{H}$ and Seki N: microRNA1/133a and microRNA-206/133b clusters: dysregulation and functional roles in human cancers. Oncotarget 3(1): 9-21, 2012.

14 Han C, Yu Z, Duan Z and Kan Q: Role of microRNA-1 in human cancer and its therapeutic potentials. Biomed Res Int 2014: 428371, 2014
15 Tominaga E, Yuasa K, Shimazaki S and Hijikata T: MicroRNA-1 targets Slug and endows lung cancer A549 cells with epithelial and anti-tumorigenic properties. Exp Cell Res 319(3): 77-88, 2013.

16 Osaka E, Yang X, Shen JK, Yang P, Feng Y, Mankin HJ, Hornicek FJ and Duan Z: MicroRNA-1 (miR-1) inhibits chordoma cell migration and invasion by targeting slug. J Orthop Res 32(8): 1075-1082, 2014.

$17 \mathrm{Li} \mathrm{L}$, Sarver AL, Alamgir S and Subramanian S: Downregulation of microRNAs miR-1, -206 and -29 stabilizes PAX3 and CCND2 expression in rhabdomyosarcoma. Lab Invest 92(4): 571-583, 2012

18 Jiang C, Chen H, Shao L and Wang Q: MicroRNA-1 functions as a potential tumor suppressor in osteosarcoma by targeting Med1 and Med31. Oncol Rep 32(3): 1249-1256, 2014.

19 Niu J, Sun Y, Guo Q, Niu D and Liu B: miR-1 inhibits cell growth, migration, and invasion by targeting VEGFA in osteosarcoma cells. Dis Markers 2016: 7068986, 2016.

20 Chi N and Epstein JA: Getting your Pax straight: Pax proteins in development and disease. Trends Genet 18(1): 41-47, 2002.

21 Fang WH, Wang Q, Li HM, Ahmed M, Kumar P and Kumar S: PAX3 in neuroblastoma: oncogenic potential, chemosensitivity and signalling pathways. J Cell Mol Med 18(1): 38-48, 2014.

22 Liu Q, Yang G and Qian Y: Loss of MicroRNA-489-3p promotes osteosarcoma metastasis by activating PAX3-MET pathway. Mol Carcinog 56(4): 1312-1321, 2017.

23 Nasser MW, Datta J, Nuovo G, Kutay H, Motiwala T, Majumder S, Wang B, Suster S, Jacob ST and Ghoshal K: Down-regulation of micro-RNA-1 (miR-1) in lung cancer. Suppression of tumorigenic property of lung cancer cells and their sensitization to doxorubicin-induced apoptosis by miR-1. J Biol Chem 283(48): 33394-33405, 2008.

24 Xiao H, Zeng J, Li H, Chen K, Yu G, Hu J, Tang K, Zhou H, Huang Q, Li A, Li Y, Ye Z, Wang J and Xu H: MiR-1 downregulation correlates with poor survival in clear cell renal cell carcinoma where it interferes with cell cycle regulation and metastasis. Oncotarget 6(15): 13201-13215, 2015.

25 Datta J, Kutay H, Nasser MW, Nuovo GJ, Wang B, Majumder S, Liu CG, Volinia S, Croce CM, Schmittgen TD, Ghoshal K and Jacob ST: Methylation mediated silencing of MicroRNA-1 gene and its role in hepatocellular carcinogenesis. Cancer Res 68(13): 5049-5058, 2008.

26 Jiang S, Zhao C, Yang X, Li X, Pan Q, Huang H, Wen X, Shan H, Li Q, Du Y and Zhao Y: miR-1 suppresses the growth of esophageal squamous cell carcinoma in vivo and in vitro through the downregulation of MET, cyclin D1 and CDK4 expression. Int J Mol Med 38(1): 113-122, 2016.

27 Diller L, Kassel J, Nelson CE, Gryka MA, Litwak G, Gebhardt M, Bressac B, Ozturk M, Baker SJ, Vogelstein B, et al.: p53 functions as a cell cycle control protein in osteosarcomas. Mol Cell Biol 10(11): 5772-5781, 1990.

28 Rao-Bindal K and Kleinerman ES: Epigenetic regulation of apoptosis and cell cycle in osteosarcoma. Sarcoma 2011: 679457, 2011.

29 Chen J, Xia L, Wu X, Xu L, Nie D, Shi J, Xu X, Ni L, Ju S, Zhu $\mathrm{H}$ and Shi W: Clinical significance and prognostic value of PAX3 expression in human glioma. J Mol Neurosci 47(1): 52-58, 2012.

Received October 4, 2018

Revised October 18, 2018

Accepted October 19, 2018 